\title{
La nutrición como condicionante de la salud de la piel
}

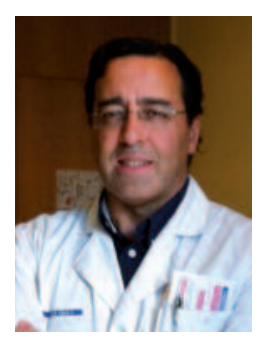

Venancio Martínez Suárez

Pediatra. Centro de Salud El Llano. Gijón (Asturias).

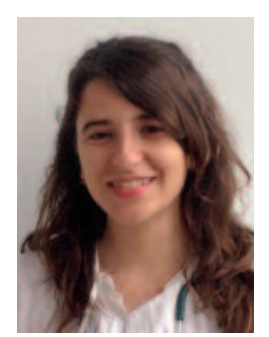

Alejandra Méndez Sánchez

MIR de Pediatría. Hospital Universitario Central de Asturias. Oviedo (Asturias).

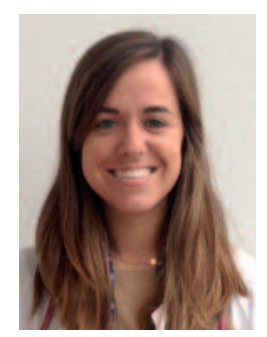

Belén Pérez Basterrechea MIR de Pediatría. Hospital Universitario Central de Asturias. Oviedo (Asturias).
Una gran variedad de factores influyen tanto en la integridad estructural como en las diversas funciones de la piel. La carga genética, la exposición a la luz solar y a determinados ambientes, el padecimiento de enfermedades crónicas, el consumo de medicamentos y la aplicación de terapias hormonales, la higiene y el estrés, son todas ellas circunstancias que se han relacionado con determinados estados patológicos y de perturbación de su normalidad. Entre ellos, la nutrición ha sido considerada históricamente como uno de los primeros y más importantes condicionantes de la salud de la piel. No obstante, su impacto sobre la fisiología normal y los mecanismos implicados en algunas alteraciones son todavía motivo de controversia ${ }^{1,2}$.

\section{PRINCIPALES NUTRIENTES IMPLICADOS EN LA SALUD DÉRMICA}

Existe poca información suficientemente contrastada sobre los efectos en la piel de los aportes de los diferentes nutrientes ${ }^{2,3}$. El agua representa aproximadamente el $70 \%$ de su composición, a la que en su variación pueden acompañarla diversas sales con valor nutricional. De hecho, el estado de hidratación se considera un parámetro de gran relevancia, tanto en condiciones de salud como en situaciones de enfermedad o fisiológicas especiales; repercute además de forma fundamental en el bienestar de la persona. La piel es un elemento clave del balance acuoso del individuo, y las pérdidas insensibles están aumentadas significativamente durante los estados de hiperventilación, la sudoración profusa o en condiciones ambientales de baja humedad y elevada temperatura ${ }^{4}$. A la hora de alimentarse, los hidratos de carbono complejos deben dominar sobre los simples, aunque teniendo en cuenta el papel nutritivo esencial de la lactosa en los primeros años de vida. $\mathrm{Si}$ bien los azúcares no desempeñan una función particular en la piel, la glucosa es la primera fuente de energía para sus diferentes tipos celulares; proporcionan, además, sustrato para la glicosilación de las proteínas y lípidos que componen el medio extracelular y forman parte de elementos plásticos esenciales de sus diferentes células. Desde hace años sabemos que los niveles alterados de glucosa en la piel pueden causar cambios estructurales y en las funciones de barre$\mathrm{ra}^{5}$, siendo la concentración elevada inhibidora de la proliferación de queratinocitos, con las consecuencias que esto pueda tener en los procesos de proliferación reparadora y cicatrización, tal como ocurre en la diabetes. A través de los estudios de las situaciones de desnutrición, hemos ido 
conociendo que la falta de proteinas en la dieta da lugar a hipotrofia y distrofia dérmica, a pelo frágil, despigmentado, fácilmente desprendible y que crece más lentamente, con puntas abiertas y delgado. Y diferentes aminoácidos han mostrado una función estimuladora de la síntesis de colágeno dérmico: la prolina y su precursor, el glutamato, aumentan de manera significativa la síntesis de esta proteína por los fibroblastos humanos ${ }^{1}$. Esta actividad de ambas moléculas podría tener algún papel in vivo en la protección de la piel frente a los daños de la irradiación ultravioleta (UV), su envejecimiento precoz y retraso en la cicatrización de heridas, aunque los resultados de los estudios publicados son dispares. En cuanto al componente graso, aparte de su función energética (la piel es lugar de síntesis y almacenaje), debe señalarse la importancia de algunos lípidos en la síntesis de mediadores locales a los que se les va atribuyendo una relevancia funcional cada vez mayor. Las principales moléculas que se han relacionado con la salud dérmica son la ceramida, el colesterol y algunos ácidos grasos. En particular, la ceramida es un componente clave de los lípidos de función barrera y condicionante de la permeabilidad en el dominio extracelular de la capa córnea ${ }^{6}$. Junto a sus metabolitos, parece intervenir en las funciones de señalización celular, pro- liferación, diferenciación y apoptosis en queratinocitos epidérmicos. Igualmente, se ha referido su participación en el desarrollo de ciertas enfermedades que cursan con alteración de la barrera permeable, como la dermatitis atópica y la psoriasis. Se ha probado que dos de sus metabolitos (la ceramida-1-fosfato y la esfingosina-1-fosfato) estimulan la producción por los queratinocitos de sustancias que participan en la inmunidad innata (betadefensinas y catelicidina, péptido antimicrobiano $)^{6}$, por lo que se les atribuye algún papel en la defensa dérmica local ${ }^{7}$.

Respecto al papel que puedan desempeñar algunos micronutrientes (tabla 1$)^{1,3}$, en los últimos años se ha prestado gran atención a las alteraciones y enfermedades de la piel debidas al déficit de algunas vitaminas. Se ha reconocido para la vitamina A y sus derivados (retinoides y carotenoides) un papel importante en la regulación de la proliferación, diferenciación y apoptosis de diferentes tipos celulares, incluyendo células de la piel. Investigaciones recientes han demostrado que los retinoides podrían potenciar la reparación de la piel dañada por la radiación UV, aumentando la multiplicación de queratinocitos epidérmicos y fibroblastos dérmicos y mediante la inhibición de la expresión de metaloproteasas que degradan la matriz extracelular, dando lugar

Tabla 1. Trastornos de la piel asociados a deficiencias específicas de micronutrientes*

\begin{tabular}{l|l}
\hline Deficiencia & Trastorno dérmico \\
\hline Vitamina A & Dermatitis atópica, retraso en la reparación de las heridas \\
\hline Vitamina C & $\begin{array}{l}\text { Adelgazamiento del estrato córneo, hemorragias subcutáneas y retraso en la curación } \\
\text { de las heridas }\end{array}$ \\
\hline Vitamina D & Dermatitis atópica \\
\hline Vitamina E & Ulceraciones dérmicas, cambios en el entrecruzamiento de las fibras de colágeno \\
\hline Zinc & Epidermólisis ampollosa, dermatitis atópica \\
\hline Cobre & Enfermedad de Menkes \\
\hline Selenio & Psoriasis, epidermólisis ampollosa y ciertos tumores de piel \\
\hline
\end{tabular}

${ }^{*}$ Resumen de las referencias citadas en el texto. 
a aumento de la proteína total y su concentración en ella. También podrían modular la proliferación epidérmica en la piel en estado hiperproliferativo, tal como ocurre en la psoriasis. De hecho, se les ha asignado un potencial significativo en la prevención y tratamiento de otras enfermedades de la piel, tales como la ictiosis, cáncer de piel y acné. Por el contrario, la hipovitaminosis A también se asocia con retraso en la cicatrización de las heridas. Respecto a la vitamina $C$, es un potente antioxidante soluble en agua que parece atenuar los daños de la irradiación solar en la piel. Disminuye significativamente la producción de radicales libres tras la exposición a la luz UV, protegiendo las células del estrés oxidativo, y tiene una función adicional en la cicatrización de heridas mediante el aumento de procolágeno y la síntesis de colágeno, que estimulan la formación de la barrera de la piel. Se ha relacionado, además, con un aumento significativo del contenido acuoso de la epidermis, mejorando la hidratación de la piel. Aparte de las fuentes alimentarias naturales, la vitamina $D$ se sintetiza en la piel humana después de la irradiación $\mathrm{UV} \mathrm{B}^{8}$, donde como función biológica primaria su metabolito activo 1,25-dihidroxivitamina $\mathrm{D}_{3}$ estimula la defensa antimicrobiana mediante el aumento de los niveles del catelicidina. Además, inhibe selectivamente la proliferación de queratinocitos y podría modular la inflamación, la angiogénesis y la cicatrización de heridas mediante la regulación de la producción de AMPc. Por otra parte, estudios recientes han relacionado los niveles de vitamina $\mathrm{D}$ con la gravedad del eccema atópico. Otra vitamina liposoluble, la vitamina $E$, es un antioxidante que modula los daños producidos por radicales libres originados tras la exposición a la irradiación UV e inhibe significativamente la degradación del colágeno. Junto con sus propiedades antioxidantes, podría regular negativamente la inflamación de la piel atenuando la producción de prostaglandinas, citocinas proinflamatorias, ciclooxigeneasa-2 y NADPH oxidasa $^{1,3}$.
Entre los minerales, el zinc, el cobre y el selenio podrían tener una función importante en la preservación de una piel sana ${ }^{1}$. El zinc es un nutriente esencial y cofactor de numerosas metaloenzimas, que protege contra el daño solar mediante la absorción de la irradiación UV y limita su penetración intradérmica. Por otra parte, la deficiencia de zinc se ha observado en la epidermólisis ampollosa, y en pacientes con dermatitis atópica se halló una disminución significativa en los niveles de este metal. Una enfermedad congénita poco frecuente, conocida como acrodermatitis enteropática (dermatitis grave, déficit en el crecimiento y diarrea) se debe a la incapacidad del niño para absorber en forma adecuada el zinc, es potencialmente mortal y responde satisfactoriamente a su reposición mediante suplementos. Como el zinc y las vitaminas $\mathrm{C}$ y E, el cobre también actúa como antioxidante, protegiendo la piel del daño causado por la radiación UV. Además, parece estimular la maduración de colágeno, lo que podría ser crítico para mejorar la elasticidad de la piel y su espesor. Participa en la síntesis de melanina, favoreciendo la pigmentación de la piel y el cabello. El síndrome de Menkes, también denominado del cabello «acerado» (pelo blanco y plata) o «ensortijado», es una enfermedad metabólica multisistémica grave causada por la deficiencia en el transporte transmembrana de cobre, con piel arrugada especialmente en el cuello, pelo áspero y quebradizo. En relación con el selenio, se le considera protector de la piel frente al estrés oxidativo de los rayos UV a través de la estimulación de las enzimas antioxidantes glutatión peroxidasa y tiorredoxina reductasa, presentes en la membrana plasmática de los queratinocitos epidérmicos. Ha sido considerado para el tratamiento de la psoriasis, que muestra disminución de los niveles de glutatión peroxidasa ${ }^{9}$. Su deficiencia se ha detectado en pacientes con epidermólisis ampollosa distrófica recesiva, por lo que su nivel plasmático se acepta como un marcador en esta enfermedad. Por otra parte, su deficiencia se asocia con un mayor riesgo de cáncer de piel. 
Como comentario final, respecto a la utilidad de los probióticos en la dermatitis atópica, los estudios realizados han sido múltiples y con resultados contradictorios. Puede afirmarse que no existen datos suficientes sobre su valor preventivo o terapéutico ${ }^{10}$, aunque desde la información proveniente en otro tipo de patologías se puede aceptar una buena tolerancia y la ausencia de efectos nocivos significativos.

\section{RELACIÓN CON LA DIETA DE ALGUNAS ENFERMEDADES DE LA PIEL}

Dermatitis atópica (DA). El papel de la alergia alimentaria en la patogenia de la DA continua siendo controvertido. Sin embargo, los estudios apuntan a que en lactantes y niños pequeños, los alérgenos alimentarios pueden provocar o agravar lesiones de DA en la piel. En los adultos, la alergia alimentaria como causa desencadenante es muy rara. Sin embargo, en pacientes con alergia alimentaria que tienen DA, la ingestión del alimento puede provocar todo el espectro de síntomas mediados por IgE, síndrome de alergia oral y shocks anafilácticos. El $90 \%$ de las alergias alimentarias se producen por seis alimentos: trigo, leche, soja, pescado, huevos y cacahuetes. Una revisión de la Cochrane publicada en 2008 señaló que no parece haber ningún beneficio en la eliminación del huevo y la leche de la dieta en los participantes con eccema atópico ${ }^{11}$. Por último, la administración de suplementos en la dieta de aceite de onagra y de DHA (ácido docosahexaenoico, un ácido graso omega-3) pueden aportar algún beneficio clínico.

Acné vulgar. El estado actual de la relación entre la dieta y el acné no es claro y es motivo frecuente de debate en los foros dermatológicos. Por un lado, la Academia Americana de Dermatología publicó sus recomendaciones en 2007, en las que sugería que la restricción calórica no tiene ningún beneficio en el tratamiento del acné y que no hay pruebas suficientes para vincular el acné con el consumo de ciertos «alimentos enemigos».
En el año 2011 se publicó un metaanálisis acerca del impacto de la dieta en el acné. Los factores dietéticos ${ }^{12}$, incluyendo un alto índice glucémico, leche, chocolate, sal, aceite y comidas con alto porcentaje en grasas, han sido evaluados y comparados, hallándose una fuerte relación entre la ingesta de alimentos con alto índice glucémico y el acné. En el caso de la relación entre las dietas con alto contenido graso y acné, la evidencia científica es menos robusta.

Dermatitis herpetiforme. Existe una relación directa entre la dieta y la dermatitis herpetiforme. Su expresión es gluten-dependiente; por tanto, una dieta sin gluten es la base de su tratamiento, y alivia además los síntomas gastrointestinales que pudieran estar presentes, la malabsorción de nutrientes (de hierro, vitamina $\mathrm{B}_{12}$ y ácido fólico) y la manifestación dermatológica ${ }^{13}$.

Psoriasis. Los factores dietéticos que se han relacionado con la enfermedad psoriásica se resumen en la tabla $2^{14}$. Faltan estudios que demuestren la relación entre psoriasis y nutrición, pero hay una serie de alimentos que se debe recomendar eliminar de la dieta porque podrían agravar la enfermedad existente o actuar como disparador en su inicio: café y té negro, chocolate, yerba mate, pimienta, comidas ahumadas, ternera y glutamato monosódico, además del tabaco y el alcohol.

Otras enfermedades de la piel podrían beneficiarse de un control alimentario ${ }^{15}$, entre ellas el pénfigo (enfermedad autoinmunitaria de la piel y las mucosas que causa vesículas, bullas y úlceras cutáneas): algunos estudios indican que las comidas ricas en tioles y taninos pueden llevar a su exacerbación. La urticaria y el prurito generalizado: casi dos de cada tres reacciones urticariales pueden ser causadas por alergia a algún alimento; deberían realizarse estudios en dichos pacientes para reconocer el elemento de la dieta responsable e iniciar su exclusión. La restricción de proteínas en la dieta ha resultado reducir los síntomas en el prurito urémico y se ha postulado que la suplementación con PUFA (ácidos grasos poliinsaturados) en la dieta del prurito colestásico podría 
Tabla 2. Factores dietéticos que se han asociado con el desarrollo y actividad de la psoriasis*

\begin{tabular}{l|l}
\hline Ingesta calórica/obesidad & $\begin{array}{l}\text { La obesidad se relaciona con una mayor incidencia y gravedad de la psoriasis; } \\
\text { también influye en una peor respuesta al tratamiento. Se debe intervenir en } \\
\text { su prevención y control }\end{array}$ \\
\hline Alcohol & $\begin{array}{l}\text { Su consumo agrava las lesiones cutáneas, además de acompañarse } \\
\text { frecuentemente de dietas y modos de vida que favorecen la obesidad }\end{array}$ \\
\hline LPUFA & $\begin{array}{l}\text { Aunque con poca consistencia todavía, algunos estudios señalan que el } \\
\text { consumo de pescado y omega-3 mejoran la psoriasis cutánea }\end{array}$ \\
\hline Gluten & $\begin{array}{l}\text { La dieta sin gluten en pacientes psoriásicos y anticuerpos antigliadina } \\
\text { positivos puede ser beneficiosa }\end{array}$ \\
\hline Estrés oxidativo & $\begin{array}{l}\text { El consumo de frutas y verduras ricas en antioxidantes (vitaminas C y E, } \\
\text { betacaroteno y selenio) podría ser beneficioso }\end{array}$ \\
\hline
\end{tabular}

*Resumido de la referencia bibliográfica 1.

LPUFA: ácidos grasos poliinsaturados de cadena larga.

ser beneficiosa. En la rosácea, el té, el café, las bebidas calientes, el tabaco, el alcohol y la comida picante son responsables de precipitar episodios de flushing. En casos de vitíligo se ha descrito que suplementos orales con antioxidantes (ácido alfa-lipoico y vitamina $\mathrm{B}_{12}$ ) antes y durante la fototerapia con UV B mejora significativamente los resultados de esta última. En el herpes se ha publicado que la recurrencia de lesiones podría estar en relación con la ingesta de azúcar refinado o comida rica en arginina, aunque falta todavía evidencia científica. Y para la esclerodermia, algunos autores aconsejan evitar en la dieta la presencia de fibra; además, se ha observado una mejoría en la piel de estos pacientes cuando se les administran suplementos de vitamina E.

Existen múltiples trastornos nutricionales con manifestaciones dermatológicas. Son tanto trastornos carenciales como superávits alimentarios. Entre los primeros destacan el kwashiorkor, el marasmo, la pelagra y el escorbuto. Estas patologías se han estudiado en períodos de carencias nutricionales, aunque actualmente persisten en los países pobres. Entre los problemas del superávit alimentario podemos destacar: la carotenemia por el consumo excesivo de zanahorias y naranja; la licopenemia, afección cutánea poco frecuente, pro- ducida por el consumo excesivo de tomates o caquis. Ambas presentan una coloración anaranjada en palmas y plantas por la lenta conversión de caroteno a vitamina A y que desaparece al cambiar los hábitos alimentarios. La hiperlipidemia, que produce un aumento de la incidencia de xantelasmas. La enfermedad de Refsum se produce por aumento del ácido fítico, muy importante en la dieta de determinadas culturas, y produce ictiosis, trastornos neurológicos y visuales.

En la relación de la piely la obesidad ${ }^{16}$ existen una serie de manifestaciones dérmicas más frecuentes en pacientes obesos y que se enumeran según su mecanismo fisiopatológico en la tabla 3.

Cualquier alteración de la dieta en forma de deficiencia nutricional o exceso de algunos componentes pueden perturbar el equilibrio de la piel. Las modificaciones dietéticas pueden ayudar en la prevención de recurrencias de algunas patologías cutáneas y en el alivio de sus síntomas. Esto es algo que el dermatólogo y cualquier médico deben conocer, ya que la prescripción de recomendaciones alimentarias, de normas directas y consejos nutricionales pueden ayudar a su paciente a mejorar su estado de salud y a mantener una piel sana. 
Tabla 3. Alteraciones dérmicas en la obesidad y sus condicionantes fisiopatológicos*

\begin{tabular}{l|l}
\hline $\begin{array}{l}\text { Acatosis nigricans, fibromas péndulos o blancos, } \\
\text { acrocordones o verrugas alargadas }\end{array}$ & Por resistencia a la insulina \\
\hline $\begin{array}{l}\text { Acné, hirsutismo y alopecia androgénica } \\
\text { Intertrigo candidiásico o con sobreinfección bacteriana }\end{array}$ & $\begin{array}{l}\text { Por hiperandrogenismo en mujeres } \\
\text { la higiene corporal }\end{array}$ \\
\hline $\begin{array}{l}\text { Estrías por distensión, lipodistrofia benigna, } \\
\text { hiperqueratosis plantar, insuficiencia venosa periférica, } \\
\text { linfedema }\end{array}$ & Por causas mecánicas \\
\hline Úlceras por presión, cicatrización lenta & Por hospitalización y sedentarismo \\
\hline Envejecimiento cutáneo precoz & $\begin{array}{l}\text { Por aumento de la adiposidad general y localizada, } \\
\text { desequilibrios metabólicos asociados }\end{array}$ \\
\hline
\end{tabular}

${ }^{*}$ Resumido de las referencias bibliográficas 1 y 16.

\section{BIBLIOGRAFÍA}

1. Park K. Role of micronutrients in skin health and function. Biomol Ther. 2015;23:207-17.

2. Lakdawala N, Babalola O, Fedeles F, McCusker M, Ricketts ], Whitaker-Worth $\mathrm{D}$, et al. The role of nutrition in dermatologic diseases: facts and controversies. Clin Dermatol. 2013;31: 677-700.

3. Liakou Al, Theodorakis MJ, Melnik BC, Pappas A, Zouboulis CC. Nutritional clinical studies in dermatology. J Drugs Dermatol. 2013;12(10):1104-9.

4. Martínez V. Criterios de hidratación dentro de la asistencia infantil integral. Documento Consenso de Pautas de Hidratación en la Asistencia Integral coordinado por la Sociedad Española de Nutrición Comunitaria. Madrid: IMC; 2013. p. 17-23.

5. Van Hattem S, Bootsma AH, Thio HB. Skin manifestations of diabetes. Cleve Clin J Med. 2008;75:772-7.

6. Uchida Y. Ceramide signaling in mammalian epidermis. Biochim Biophys Acta. 2014;1841:453-62.

7. Kim YI, Park K, Kim JY, Seo HS, Shin KO, Lee YM, et al. An endoplasmic reticulum stress-initiated sphingolipid metabolite, ceramide-1-phosphate, regulates epithelial innate immunity by stimulating beta-defensin production. Mol Cell Biol. 2014; 34:4368-78.

8. Martínez V, Dalmau J. Vitamina D: más allá de sus efectos sobre el metabolismo óseo. Pediatr Integral. 2013;17(10):728-33.
9. Naziroglu M, Yildiz K, Tamturk B, Erturan I, Flores-Arce M. Selenium and psoriasis. Biol Trace Elem Res. 2012;150:3-9.

10. Boyle RJ, Bath-Hextall FJ, Leonardi-Bee J, Murrell DF, Tang ML. Probiotics for treating eczema. Cochrane Database Syst Rev. 2008;(4):CD006135.

11. Bath-Hextall F, Delamere FM, Williams HC. Dietary exclusions for established atopic eczema. Cochrane Database Syst Rev. 2008;(1):CD005203.

12. Smith RN, Mann NJ, Braue A, Mäkeläinen H, Varigos GA. The effect of a high-protein, low glycemic-load diet versus a conventional, high-glycemic-load diet on biochemical parameters associated with acne vulgaris: a randomized, investigator- masked, controlled trial. J Am Acad Dermatol. 2007; 57(2):247-56.

13. Cardones AR, Hall RP. Pathophysiology of dermatitis herpetiformis: a model for cutaneous manifestations of gastrointestinal inflammation. Immunol Allergy Clin North Am. 2012; 32(2): 263-74.

14. Johnson JA, Ma C, Kanada KN, Armstrong AW. Diet and nutrition in psoriasis: analysis of the National Health and Nutrition Examination Survey (NHANES) in the United States. J Eur Acad Dermatol Venereol. 2014;28(3):327-32.

15. Puerto L, Tejero P. Alimentación y nutrición: repercusión en la salud y belleza de la piel. Nutr Clin Diet Hosp. 2013;33(2): 56-65.

16. García H. Dermatological complications of obesity. Am J Clin Dermatol. 2002;3(7):497-506. 